\title{
Diferentes tipos de poda na produção da videira cv. bordô
}

\section{Different types of pruning in the yield of cv. bordô grapes}

\author{
Marcelo Barbosa Malgarim ${ }^{1 *}$; Ana Paula Afinovicz²; Maria Denize Euleuterio 3 ; \\ Fernando Filus Pierin²; Joyce Soares Dias ${ }^{3}$; Marcello Sozim²
}

\begin{abstract}
Resumo
Este experimento foi realizado em um vinhedo localizado na região Centro - Sul do Estado Paraná, com o objetivo de avaliar diferentes tipos de poda na cultura da videira cv. Bordô na safra 2007/08. Foram utilizadas plantas com 6 anos de idade, conduzidas no sistema latada e espaçadas 3,0 x 1,0 m. As videiras foram submetidas aos tratamentos de poda esporonada (esporões com duas a três gemas), poda longa (varas de cinco a seis gemas) e poda mista (esporões e varas). As variáveis avaliadas foram: número de cachos por planta, produção por planta e massa média dos cachos. Observou-se que em relação ao número de cachos por planta houve diferenças significativas somente para poda longa em relação às demais, assim como para massa média dos cachos. Em relação à produção por planta houve diferença significativa entre todos os tratamentos sendo que a poda longa apresentou maior produção por planta, chegando a ser aproximadamente três vezes maior que a produção da poda esporonada.
\end{abstract}

Palavras-chave: Número de cachos, Vitis spp

\begin{abstract}
This experiment was conducted in a vineyard located in the Central - southern region of Parana state, aiming to evaluate different types of pruning on the culture of grapevine cv. Bordô in 2007/08 crop season. We used plants with 6 years of age, trained in trellis system and spaced $3.0 \times 1.0 \mathrm{~m}$. The vines were subjected to the treatment of short pruning (spurs with two to three buds), long pruning (branches of five to six buds) and mixed pruning (spurs and branches). The variables were: number of bunches per plant, yield per plant and average mass of bunches. Regarding the number of bunches per plant there were significant differences only for long pruning in relation to the others, as well as for average mass of bunches. For the yield per plant there were significant differences among all treatments and the long pruning had higher yield per plant, being approximately three times larger than the production of short pruning.
\end{abstract}

Key words: Number of clusters, Vitis spp

\footnotetext{
1 Eng. Agr. Dr. Professor do Curso Superior de Tecnologia em Viticultura e Enologia do Centro Agrotécnico Visconde da Graça CAVG, Pelotas, RS. E-mail: malgarim@yahoo.com

2 Eng. Agr.(a) Bolsista Secretaria de Estado da Ciência, Tecnologia e Ensino Superior (SETI/PR).

3 Graduandas e Bolsistas pela Universidade Estadual de Ponta Grossa (UEPG), PR

* Autor para correspondência
} 
A videira é podada com o fim de equilibrarse a frutificação e a vegetação (SOUSA, 1996). Em princípio, poda-se durante todo o período de repouso vegetativo, ou seja, duas ou três semanas após a queda das folhas até a semana que precede o abrolhamento, observando-se sempre os riscos de geadas tardias (CHAUVET; REYNIER, 1979).

Sem a execução da poda, a produtividade da videira não é constante e os cachos são pequenos e de baixa qualidade (MIELE; MANDELLI, 2004). A intensidade da poda dependerá da cultivar, vigor, fertilidade das gemas, clima, solo e porta-enxerto. As podas curta, média, longa e mista estão entre as intensidades existentes (SOUSA, 1996). Segundo Hidalgo (1993), a fertilidade das gemas pode ser definida como a capacidade de diferenciação de gemas vegetativas em frutíferas.

Roberto et al. (2002) constatou diferenças significativas entre as podas curtas, médias e longas para a porcentagem de gemas brotadas e porcentagem de gemas brotadas com cacho, mostrando que o número de gemas deixado no sarmento ou esporão influencia nessas características da videira 'Niagara Rosada'. Tonietto e Czermainski (1993) avaliando comportamento da videira 'Cabernet Franc' concluíram que os maiores índices de fertilidade foram encontrados nas varas com seis a doze gemas, sendo esta fertilidade mais alta na porção mediana e mais baixa na base das varas. Camargo, Mashima e Czermainski (1997) determinaram para a videira 'Perlette' no Vale do São Francisco que a poda curta afetou a produtividade pela baixa fertilidade das gemas basais.

O tipo de poda utilizada na região de Bituruna - PR, localizada no Centro Sul do Estado, devido a conhecimentos empíricos e à própria cultura da região é a poda curta (esporonada). Neste contexto, realizou-se este trabalho com o objetivo de avaliar diferentes tipos de poda na produção da videira cv. Bordô nesta região, na safra 2007/08.

$\mathrm{O}$ experimento foi realizado em um vinhedo na cidade de Bituruna região Centro - Sul do Paraná, localizado à $26^{\circ} \mathrm{S}$ e $51^{\circ} \mathrm{O}$ a uma altitude de 987 metros e clima classificado, segundo Köppen, como $\mathrm{Cfb}$. Foram utilizadas videiras cv. Bordô sobre o porta - enxerto 420-A, com seis anos de idade, conduzidas no sistema latada e com espaçamento de $3,0 \mathrm{~m} \times 1,0 \mathrm{~m}$.

Os tratamentos realizados foram: poda em cordão esporonado (esporões com duas a três gemas) praticada pelo produtor, poda mista (esporões com duas a três gemas e varas com cinco a seis gemas) e poda longa (varas com cinco a seis gemas), realizadas no dia 16 de agosto de 2007, sem a utilização de cianamida hidrogenada para quebrar a dormência.

As variáveis analisadas foram: número de cachos por planta, produção por planta e massa média de cachos por planta.

O delineamento experimental utilizado foi inteiramente casualizado com cinco repetições de duas plantas cada. Os dados foram submetidos a analise de variância no esquema inteiramente casualizado e as médias comparadas pelo teste de Tukey a 5\% de probabilidade.

Em relação ao número de cachos por planta, observou-se que houve diferença significativa somente para a poda longa (Tabela 1) a qual apresentou maior número de cachos em relação à poda mista e poda esporonada não diferiram significativamente entre si em relação a esta variável. Winkler et al. (1974) descreveram que o acúmulo de carboidratos nos ramos produtivos está estreitamente associado à formação de gema fértil, e para muitas variedades ocorre acúmulo mais rápido de amido na porção mediana dos brotos, ponto onde localiza-se o maior número de gemas frutíferas. 
Tabela 1. Avaliação do número de cachos por planta, produção por planta e massa média de cachos por planta em função de diferentes tipos de podas na cv. Bordô safra 2007/08, Bituruna - PR.

\begin{tabular}{|c|c|c|c|}
\hline \multirow{2}{*}{ Tratamentos } & Número de cachos & Produção & $\begin{array}{l}\text { Massa média de } \\
\text { cachos }\end{array}$ \\
\hline & $\left(\right.$ plantas $\left.^{-1}\right)$ & (kg. planta $\left.{ }^{-1}\right)$ & (g. cacho $^{-1}$ ) \\
\hline Poda esporonada & $83,75 \mathrm{~B}$ & $4,67 \mathrm{C}$ & $56,21 \mathrm{~B}$ \\
\hline Poda mista & $122,00 \mathrm{~B}$ & $7,81 \mathrm{~B}$ & $64,54 \mathrm{AB}$ \\
\hline Poda longa & $189,92 \mathrm{~A}$ & $12,64 \mathrm{~A}$ & $68,26 \mathrm{~A}$ \\
\hline
\end{tabular}

*Medias seguidas da mesma letra na coluna não diferem significativamente pelo teste de Tukey a $5 \%$ de probabilidade.

A massa média dos cachos apresentou diferença somente entre poda a longa e poda esporonada. Quanto à produção por planta houve diferença significativa entre todos os tratamentos. A poda longa apresentou a maior produção por planta, sendo que em relação a poda esporonada a produção foi de aproximadamente três vezes maior.

Sozim(2007)tambémobtevemaiorprodutividade utilizando a poda longa para a cv. Vênus devido ao um maior número de gemas remanescentes na poda longa o que proporcionou a formação de um maior número de cachos.

As podas dos anos anteriores têm muita influência sobre a formação das gemas. Na região são praticadas podas muito severas causando um excesso de vegetação. Este vigor induzido pela poda severa reduz a fertilidade das gemas, principalmente em cultivares apirenas (SHIKHAMANY, 1999).

Os resultados obtidos neste trabalho mostram que para poda de videira cv. Bordô na região Centro - Sul do Paraná o melhor tipo é a poda longa, pois apresentou maior produção em relação aos demais tipos de poda, porém as plantas submetidas a este tipo de poda ao longo dos anos podem perder vigor devido à utilização das reservas para nutrição do maior número de varas e de cachos, portanto para o trabalho proposto a poda mista é a mais adequada, porque apresentou um aumento na produção em relação à poda esporanada (praticada pelo produtor), e não compromete as plantas para as próximas safras.
Pode-se concluir que videiras cv. Bordô submetidas à poda longa apresentaram a maior produção.

\section{Referências}

CAMARGO, U.A.; MASHIMA, C. H.; CZERMAINSKI, A. B. C. Avaliação de cultivares de uvas apirênicas no Vale do São Francisco. Bento Gonçalves: EMBRAPACNPUV, 1997. (Comunicado Técnico, 26).

CHAUVET, M.; REYNIER, A. Manual de viticultura. 3. ed. Portugal: Narciso Correia, 1979.

HIDALGO, L. Tratado de viticultura general. Madrid: Mundi Prensa, 1993.

MIELE, A.; MANDELLI, F. Poda seca da videira. 2004. Disponível em: <http://www.cnpuv.embrapa.br/servicos/ viticultura/podaseca.html>. Acesso em: 22 fev. 2008 .

ROBERTO, S.R.; KANAI, H.T.; YANO, M.Y.; SASANO, E. M.; GENTA, W. Efeito da poda de frutificação sobre a fertilidade de gemas da videira 'Niagara Rosada“ produzida fora de época no Paraná, 2002. In: CONGRESO BRASILEIRO DE FRUTICULTURA, 17., 2002, Belém. Anais... Belém: Sociedade Brasileira de Fruticultura, 2002. Disponível em: $<\mathrm{http}: / / w w w . u f p e l . e d u . b r / s b f r u t i /$ anais_xvii_cbf/fitotecnia/009.htm>. Acesso em: 7 abr. 2008 .

SHIKHAMANY, S. D. Physiology and cultural practices to produce seedless grapes in tropical enviroments. In: CONGRESSO BRASILEIRO DE VITICULTURA E ENOLOGIA, 1999, Bento Gonçalves. Anais... Bento Gonçalves: Embrapa-CNPUV, 1999. p. 43-48.

SOUSA, J. S. I. Uvas para o Brasil. 2. ed. Piracicaba: Fealq, 1996.. 
SOZIM, M.; AYUB, R. A.; MALGARIM, M. B. Efeito do tipo de poda na produção e na qualidade de videira cv. Vênus. Scientia Agraria, Curitiba, v. 8, n. 2, p. 169-172, 2007.

TONIETTO, J.; CZERMAINSKI, A. B. C. Brotação e fertilidade das gemas da videira 'Cabernet Franc'.
Revista Brasileira de Fruticultura, Jaboticabal, v. 15, n. 1, p. 185-192, 1993.

WINKLER, A. J.; COOK, J. A.; KLIEWER, W. M.; LIDER, L. A. General viticulture. Berkeley: University of California Press, 1974. 